\title{
EDITORIAL: Afinal o que nos diferencia dos outros enfermeiros e dos outros profissionais?
}

\section{EDITORIAL: After all, what sets us apart from other nurses and other professionals? EDITORIAL: Después de todo, ¿qué nos diferencia de otras enfermeras y otros}

Maria Manuela Martins ${ }^{(1)}$,

(1) Escola Superior de Enfermagem do Porto (ESEP), Centro de Investigação em Tecnologias e Serviços de Saúde (CINTESIS), Porto, Portugal;

\section{Descritores}

Editorial

\section{Descriptors}

Editorial

Descriptores

Editorial

\section{Resumo}

Não há dúvida que existimos, que temos formacão específica, num enquadramento académico, que estamos presentes na prática dos cuidados, que mostramos resultados das nossas intervenções, e isso, tem sido evidente nos estudos que temos publicado, mas o que nos diferencia? São as técnicas, as conceções, o conhecimento, ou tudo isto?

\section{Abstract}

There is no doubt that we exist, that we have specific training, within an academic framework, that we are present in the practice of care, that we show results of our interventions, and this has been evident in the studies we have published, but what makes us different? Is it the techniques, the concepts, the knowledge, or all this?

\section{Resumen}

No hay duda de que existimos, que tenemos una formación específica, dentro de un marco académico, que estamos presentes en la práctica del cuidado, que mostramos resultados de nuestras intervenciones, y eso ha sido evidente en los estudios que hemos publicado, pero ¿Qué nos diferencia? ¿Son las técnicas, los conceptos, el conocimiento o todo esto?

\section{Afinal o que nos diferencia dos outros enfermeiros e dos outros profissionais?}

0 percurso que temos realizado torna-se um desafio para os leitores e autores dos artigos que temos vindo a publicar, situação que não queremos deixar passar neste e nos próximos números.

Não há dúvida que existimos, que temos formação específica, num enquadramento académico, que estamos presentes na prática dos cuidados, que mostramos resultados das nossas intervenções, e isso, tem sido evidente nos estudos que temos publicado, mas o que nos diferencia? São as técnicas, as conceções, o conhecimento, ou tudo isto?

Importa alertar os aficionados pela Enfermagem de Reabilitação, que temos que fazer estudos experimentais e desenvolver um quadro de referência que dề corpo às competências que nos orientam no exercício profissional, compreender a influência dos metaparadigmas de enfermagem no processo de decisão clinica, mas também no âmbito da formação, supervisão e gestão. Recordemos que o desenvolvimento de competências são consideradas, consensualmente, por psicólogos, sociólogos, filósofos, e até por enfermeiros, como conhecimentos, habilidades técnicas e atitudes comportamentais, que o indivíduo possui. Importa então lembrar que o conhecimento está ligado ao que aprendemos na nossa vida académica, já as habilidades relacionam-se com a nossa vivência, a prática e o domínio adquirido e, por último, as atitudes relacionam-se com o comportamento humano, os nossos valores, sentimentos e emoções, o que nos encaminha para encontrar modelos que sirvam o cuidado de reabilitação. 
Recordemos que os cidadãos esperam que os enfermeiros de reabilitação apresentem um perfil de competências comuns e um conjunto de competências clínicas especializadas. As "Competências comuns" são as competências partilhadas por todos os enfermeiros especialistas, independentemente, da sua área de especialidade, demonstradas através da sua elevada capacidade de conceção, gestão e supervisão de cuidados e, ainda, através de um suporte efetivo ao exercício profissional especializado no âmbito da formação, investigação e assessoria (Regulamento $n^{\circ}$ 122/2011).

A especificidade dos enfermeiros de Reabilitação tem visibilidade a partir das competências especializadas e assim, recordemos: cuida de pessoas com necessidades especiais, ao longo do ciclo de vida, em todos os contextos da prática de cuidados; capacita a pessoa com deficiência, limitação da atividade e/ou restrição da participação para a reinserção e exercício da cidadania e maximiza a funcionalidade desenvolvendo as capacidades da pessoa (Regulamento n. ${ }^{\circ}$ 125/2011).

É com este olhar, que, de momento, nos pautamos na organização dos artigos que publicamos. Por isso, em cada número, tentaremos agrupar artigos que respondam a estas áreas especificas.

No presente número, poderão ver que a maior proporção de artigos recai sobre a capacitação de pessoa com deficiência, limitação da atividade e/ou restrição da participação para a reinserção e exercício da cidadania, mas pretendemos vir a equilibrar entre as três áreas, e iniciar, ainda, a publicação de artigos em áreas comuns.

Não estamos agradados com o trabalho que temos desenvolvido e gostaríamos de ter mais Enfermeiros de Reabilitação a pensar na conceção dos cuidados. Reavivemos o modelo de competências americano (2014, Association of Rehabilitation Nurses) onde emerge um modelo com mais clareza na conceção dos cuidados, apontando para quatro domínios: promover uma vida com sucesso, liderança, cuidados interprofissionais e intervenções conduzidas pelos enfermeiros que abrange 14 competências. Neste enquadramento, a associação Norte Americana reconhece que o enfermeiro de reabilitação é um gestor de cuidados à pessoa com deficiência e em condições crónicas de saúde ao longo do ciclo vital, porque atendem a pessoa como um todo. Na sua intervenção, promove o sucesso na vida e reconhece a necessidade de bem viver, procura a melhor evidência para as suas intervenções, valorizando a educação da pessoa e dos seus cuidadores, e a reconhecer que cada pessoa faz parte de uma família e de uma comunidade.

Uma visão centrada na pessoa, na saúde e na enfermagem antecipa a necessidade de o Enfermeiro de Reabilitação ter que dedicar tempo ao processo de educação para a saúde, no público, que é alvo dos seus cuidados. As mudanças físicas, emocionais, sociais ou ambientais da pessoa, com deficiência ou incapacidade, exigem reajustes no processo de promoção da saúde e prevenção da evolução da doença.

Acreditamos que os Enfermeiros de Reabilitação têm que investir em novas terapêuticas a fim de criar sucesso no bem viver das pessoas, visando a capacitação e o empoderamento para fazer face à continuidade da sua vida, pelo que, esperamos pelos vossos estudos, para nos tornarmos mais resilientes, mesmo na adversidade.

\section{Referências}

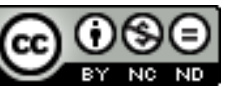

Este trabalho encontra-se publicado com a Licença Internacional Creative Commons Atribuição-NãoComercial-SemDerivações 4.0.

Direitos de Autor (c) 2021 Revista Portuguesa de Enfermagem de Reabilitação 